\title{
Warstwy pośrednie nakładane metodą tamponową
}

\author{
Intermediate layers deposited \\ by the brush plating method
}

\section{Streszczenie}

W artykule przedstawiono wyniki badań warstw pośrednich nakładanych metodą tamponową.

Przedmiotem badań były warstwy metalowe $(\mathrm{Cu}, \mathrm{Ni})$ i warstwy kompozytowe $\left(\mathrm{Cu}+\mathrm{Al}_{2} \mathrm{O}_{3}, \mathrm{Ni}+\mathrm{Al}_{2} \mathrm{O}_{3}\right)$, zastosowane do spajania ceramiki z metalami. Materiały łączono metodą zgrzewania dyfuzyjnego. Przedstawiono wyniki badań metalograficznych, pomiarów mikrotwardości i wyniki prób ścinania otrzymanych złączy.

\section{Abstract}

The paper presents the results of the investigation of intermediate layers deposited by the brush plating method. The metal $(\mathrm{Cu}, \mathrm{Ni})$ and composite metal-ceramic $\left(\mathrm{Cu}+\mathrm{Al}_{2} \mathrm{O}_{3}, \mathrm{Ni}+\mathrm{Al}_{2} \mathrm{O}_{3}\right)$ intermediate layers have been produced in frame of the research. The diffusion bonding method was used to obtain ceramic-metal joints with intermediate layers. Results of metallography, microhardness and shearing tests of ceramic-metal joints are presented.

\section{Wstęp}

Jednym z najważniejszych problemów w praktyce spajania ceramiki $z$ metalami jest występowanie w złączu spajanym znacznych naprężeń własnych, wynikających z różnic właściwości fizycznych i mechanicznych łączonych materiałów. Na poziom generowanych naprężeń istotny wpływ ma różnica między współczynnikami rozszerzalności cieplnej ceramiki i metalu oraz moduł sprężystości podłużnej i granica plastyczności metalu.

W celu zmniejszenia poziomu generowanych w złączu naprężeń stosuje się rozwiązania konstrukcyjne (najczęściej polegające na zmianie kształtu i wymiarów elementów złącza) oraz technologiczne (m.in. zastosowanie warstw lub przekładek kompensacyjnych) [1]. Kompensacyjne warstwy pośrednie lub przekładki mogą być wykonane z materiałów o wysokiej plastyczności (np. miedzi) lub materiałów, dla których wartość współczynnika rozszerzalności cieplnej jest pośrednia w stosunku do wartości charakteryzującej łączone materiały. Zastosowanie znajdują również materiały z gradientem właściwości.

Dr inż. Jarosław Grześ - Politechnika Warszawska.
Warstwy pośrednie są wytwarzane kilkoma metodami. Do najbardziej rozpowszechnionych należy metoda metalizacji proszkowej. Stosuje się również chemiczne lub galwaniczne metody nakładania warstw pośrednich. Metoda tamponowa (ang. brush plating, selective plating, spot plating, swab plating) jest jedną z odmian galwanicznego nakładania warstw i powłok. W metodzie tej elektrolit jest przenoszony na powierzchnię elementu pokrywanego za pomocą tamponu, który jest nasunięty na elektrodę połączoną $z$ dodatnim biegunem źródła prądu. Element pokrywany połączony jest z ujemnym biegunem źródła prądu. Źródło prądu stanowi prostownik o określonych parametrach prądowo-napięciowych. W porównaniu $\mathrm{z}$ typowym procesem nakładania galwanicznego metoda tamponowa ma następujące zalety:

- krótszy czas nakładania powłoki (ok.10 $\div 20$ razy),

- niższy koszt procesu (ze względu na znaczną materiało- i energooszczędność),

- łatwość obsługi stosowanych urządzeń i ich mobilność,

- możliwość jest nakładania warstw zarówno na podłoża metaliczne, i niemetaliczne (po uprzednim wytworzeniu warstwy przewodzącej dowolną metodą).

Stosowane w metodzie tamponowej elektrolity umożliwiają nakładanie warstw (powłok) charakteryzujących się takimi właściwościami, jak: wysoka odporność na zużycie i korozję, wysoka twardość, dobra 
Tablica I. Wybrane elektrolity i ich właściwości [2]

Table I. Selected plating solutions and their properties [2]

\begin{tabular}{|c|c|c|c|c|c|}
\hline Nazwa elektrolitu & $K_{j}, \mathrm{~g} / \mathrm{l}$ & $\mathrm{Ah} / \mathrm{dm}^{2 *} \mu \mathrm{m}$ & $S_{o}, \mu \mathrm{m} / \mathrm{min}$ & $Q_{E}, \mathrm{dm}^{2} / I^{*} \mu \mathrm{m}$ & Uwagi \\
\hline Copper Alkaline - 1 & 60 & 0,079 & 9,8 & 710,0 & niskie naprężenia wewnętrzne, dobra przyczepność \\
\hline Copper High Build Alkaline & 80 & 0,079 & 9,8 & 953,6 & niskie naprężenia pozostające, wysoka cena \\
\hline Nickel High Speed & 50 & 0,104 & 12,7 & 562,9 & \\
\hline Nickel Compact High Speed & 50 & 0,113 & 12,7 & 562,9 & \\
\hline Low Stress Nickel & 75 & 0,214 & 2,5 & 1073,0 & niska porowatość i naprężenia wewnętrzne \\
\hline Cobalt & 67 & 0,057 & 3,0 & 84,9 & wysoka cena \\
\hline Indium & 65 & 0,040 & $5-12,7$ & 952,6 & jw. \\
\hline $\begin{array}{l}\text { Cadmium Low Hydrogen } \\
\text { Non-Embritling }\end{array}$ & 100 & 0,020 & 30,0 & 1212,0 & jw. \\
\hline Silver Solution & 67,3 & b.d. & $12,7-25,4$ & 1905,0 & jw. \\
\hline Iron Solution & 20 & 0,848 & 0,025 & 320,4 & \\
\hline Tin & 50 & 0,01 & 17,0 & 481,1 & \\
\hline
\end{tabular}

zwilżalność powierzchni. Stwarzają również duże możliwości w zakresie budowy warstw. W tablicy I przedstawiono wybrane elektrolity produkcji chińskiej, mogące mieć zastosowanie do nakładania warstw pośrednich.

W artykule przedstawiono wyniki badań nad zastosowaniem metody tamponowej do nakładania warstw pośrednich, będące wynikiem prac badawczych prowadzonych w Zakładzie Inżynierii Spajania Politechniki Warszawskiej i poświęconych procesom łączenia ceramiki z metalami.

\section{Metalowe warstwy pośrednie}

W ramach prób spajania ceramiki z metalami z wykorzystaniem metalowych warstw pośrednich nakładanych metodą tamponową wykonano dwa rodzaje złączy ceramika-metal.

Pierwsze $z$ nich to ceramika tlenkowa $\mathrm{Al}_{2} \mathrm{O}_{3}$ zgrzewana dyfuzyjnie $z$ folią miedzianą o grubości $0,1 \mathrm{~mm}$. Zastosowano warstwy pośrednie $\mathrm{Cu}$ o grubości

Tablica II. Parametry nakładania warstw pośrednich $\mathrm{Cu}$ i Ni

Table II. The deposition parameters of $\mathrm{Cu}$ and $\mathrm{Ni}$ intermediate layers

\begin{tabular}{|c|c|c|c|c|}
\hline $\begin{array}{c}\text { Warstwa } \\
\text { pośrednia }\end{array}$ & Elektrolit & $\begin{array}{c}\text { Napięcie } \\
\text { nakładania } \\
\mathrm{V}\end{array}$ & $\begin{array}{c}\text { Czas nakładania } \\
\mathrm{s}\end{array}$ & $\begin{array}{c}\text { Prędkość } \\
\text { przesuwu } \\
\text { elektrody, m/min }\end{array}$ \\
\hline $\mathrm{Cu}$ & $\begin{array}{l}\text { Copper } \\
\text { Alkaline-1 }\end{array}$ & 14 & $\begin{array}{c}300(\mathrm{dla} g=10 \mu \mathrm{m}) \\
900(\mathrm{dla} g=30 \mu \mathrm{m})\end{array}$ & ok. 6 \\
\hline $\mathrm{Ni}$ & $\begin{array}{l}\text { Nickel } \\
\text { High Speed }\end{array}$ & 12 & 1800 & ok. 4 \\
\hline
\end{tabular}

Tablica III. Parametry zgrzewania dyfuzyjnego Table III. The parameters of diffusion bonding

\begin{tabular}{|l|c|c|c|c|c|}
\hline \multicolumn{1}{|c|}{ Złącza } & $\begin{array}{c}\text { Grubość } \\
\text { warstwy } \\
\text { pośredniej } \\
\mu \mathrm{m}\end{array}$ & $\begin{array}{c}\text { Temperatura } \\
\text { zgrzewania } \\
{ }^{\circ} \mathrm{C}\end{array}$ & $\begin{array}{c}\text { Czas } \\
\text { zgrzewania } \\
\mathrm{S}\end{array}$ & $\begin{array}{c}\text { Docisk } \\
\text { wstępny/ } \\
\text { końcowy } \\
\mathrm{MPa}\end{array}$ & $\begin{array}{c}\text { Próżnia } \\
\mathrm{Tr}\end{array}$ \\
\hline Cu-Cu-Al $\mathrm{O}_{3}$ & 30 & 970 & 600 & $1 / 10$ & $2^{*} 10^{-5}$ \\
\hline${\text { St3S-Ni-Si } \mathrm{N}_{4}}^{2}$ & 40 & 1270 & 3600 & $1 / 10$ & $4^{*} 10^{-6}$ \\
\hline Szybkość nagrewania $30^{\circ} \mathrm{C} / \mathrm{min}$ szybkość chłodzenia $15^{\circ} \mathrm{C} / \mathrm{min}$ & \\
\hline
\end{tabular}

10 i $30 \mu \mathrm{m}$, nałożone na powierzchnię ceramiki $\mathrm{Al}_{2} \mathrm{O}_{3}$. Przed nałożeniem warstwy pośredniej powierzchnię ceramiki oczyszczono i odtłuszczono. Następnie nałożono chemicznie cienką warstwę przewodzącą miedzi.

Drugi rodzaj badanych złączy stanowiła ceramika azotkowa $\mathrm{Si}_{3} \mathrm{~N}_{4}$ zgrzewana dyfuzyjnie ze stalą St3S. Zastosowano warstwę pośrednią Ni o grubości $40 \mu \mathrm{m}$, nałożoną na powierzchnię stali St3S. Przed nałożeniem warstwy pośredniej powierzchnię stali przygotowano, stosując standardową procedurę przewidzianą w metodzie tamponowej (czyszczenie elektrolityczne za pomoca elektrolitu Electroclean-1 i aktywowanie za pomocą elektrolitu Activator-2). Następnie w celu zwiększenia przyczepności warstwy pośredniej nałożono warstwę podkładową Ni z elektrolitu Nickel Special o grubości ok. $1 \mu \mathrm{m}$.

Metalowe warstwy pośrednie $\mathrm{Cu}$ i Ni nakładano, stosując parametry podane $\mathrm{w}$ tablicy II.

Próby zgrzewania dyfuzyjnego przeprowadzono, stosując różne czasy oraz temperatury zgrzewania. Pozytywne wyniki otrzymano dla parametrów zgrzewania zamieszczonych $\mathrm{w}$ tablicy III. W przypadku $\mathrm{Al}_{2} \mathrm{O}_{3}$ zgrzewanego dyfuzyjnie $z$ folią miedzianą z wykorzystaniem warstwy pośredniej Cu o grubości $10 \mu \mathrm{m}$ nie otrzymano trwałego połączenia.

Dla otrzymanych złączy przeprowadzono badania metalograficzne, rozkładów liniowych i powierzchniowych pierwiastków oraz pomiary mikrotwardości. $\mathrm{Na}$ podstawie badań metalograficznych złączy $\mathrm{Cu}-\mathrm{Cu}-\mathrm{Al}_{2} \mathrm{O}_{3}$ stwierdzono znacznie rozdrobnioną strukturę warstwy pośredniej $\mathrm{Cu}$ (rys. 1a). Na granicy jej połączenia z folią miedzianą zaobserwowano występowanie niewielkiej porowatości. W przypadku złączy St3S--Ni-Si ${ }_{3} \mathrm{~N}_{4}$ (rys. 1b) brak jest widocznych wad. Średnia mikrotwardość (HV 0,05) warstwy pośredniej Cu wynosiła 112, a warstwy pośredniej $\mathrm{Ni}-245$. Na rysunku 2 przedstawiono rozkłady liniowe pierwiastków.

Przeprowadzone próby wykazały przydatność metody tamponowej do nakładania warstw pośrednich. Istotnym parametrem, obok parametrów zgrzewania, 
mającym wpływ na powstanie złącza oraz na jego wytrzymałość, jest właściwy dobór grubości warstwy pośredniej.

a)

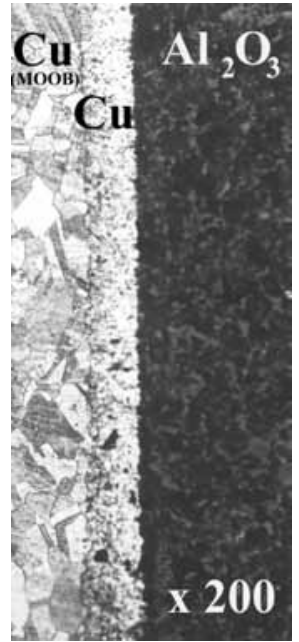

b)

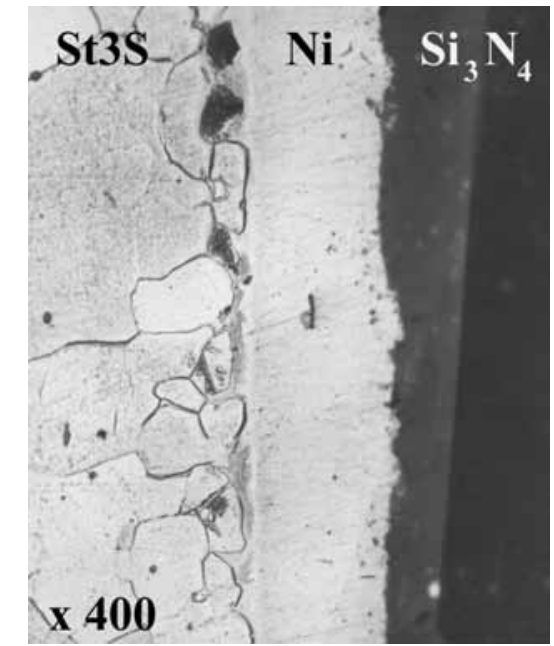

Rys. 1. Struktura złączy: a) złącze Cu-Cu-Al $\mathrm{O}_{3}$, b) złącze St3S-Ni-Si $\mathrm{N}_{4}$ Fig. 1. The cross-section of joints: a) Cu-Cu-Al $\mathrm{O}_{3}$, b) St3S-Ni-Si ${ }_{3} \mathrm{~N}_{4}$
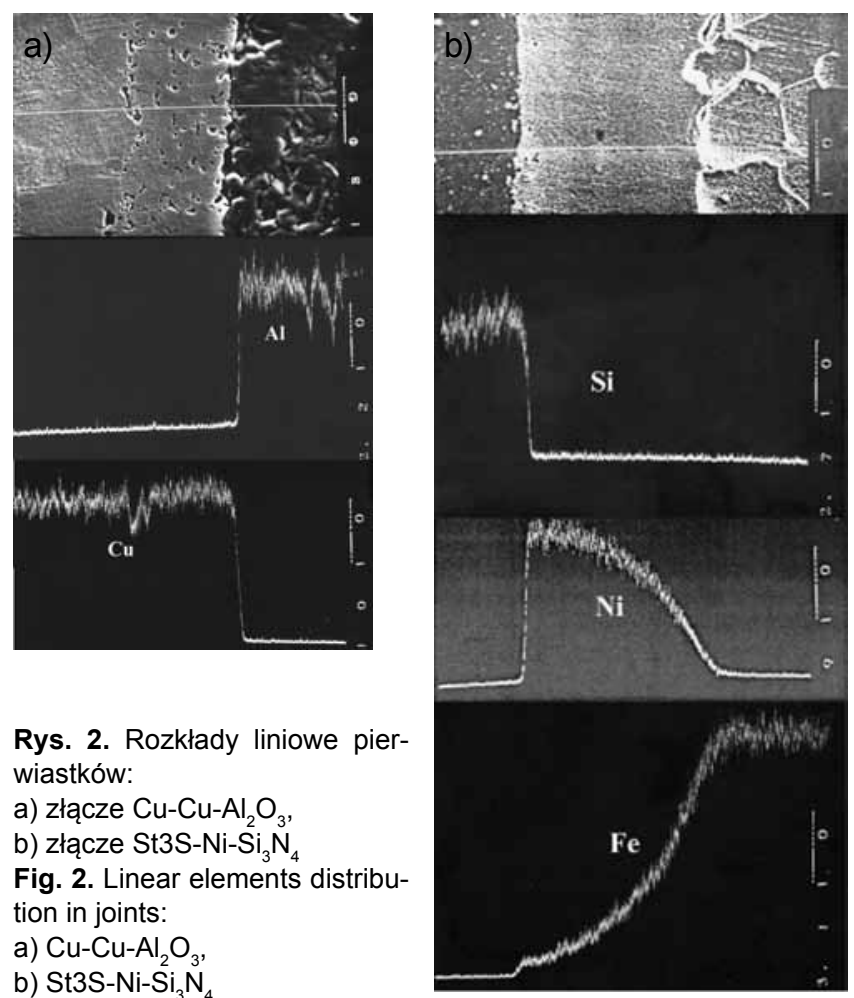

\section{Warstwy pośrednie z gradientem składu}

Metoda tamponowa umożliwia nakładanie warstw kompozytowych metalowo-ceramicznych. Właściwości warstw (m.in. mikrotwardość, struktura, zawartość fazy ceramicznej) nakładanych tą metodą zmieniają się w funkcji napięcia nakładania [3]. Dzięki temu istnieje możliwość nakładania warstw z gradientem właściwości (FGM) [4]. Najprostszy sposób wykorzystania metody tamponowej do wytworzenia warstwy pośredniej w złączu Cu-FGM-Ni został przedstawiony w publikacji [5]. W tym artykule przedstawiono wyniki badań złączy, w których warstwę pośrednią stanowiły warstwy nanokompozytowe FGM. Otrzymane wyniki badań omówiono częściowo w publikacji [6]. Badania były realizowane w ramach projektu KBN nr Z-KBN K011/T08/2000 „Nanomateriały metaliczne, ceramiczne i organiczne: synteza, budowa, właściwości, zastosowanie".

Badania wykonano na złączach stali niskowęglowej (St3S) z $\mathrm{Al}_{2} \mathrm{O}_{3}$. Jako warstwy pośrednie zastosowano gradientowe warstwy $\mathrm{Cu}+\mathrm{Al}_{2} \mathrm{O}_{3}$ oraz $\mathrm{Ni}+\mathrm{Al}_{2} \mathrm{O}_{3}$ nakładane metodą tamponową. Nakładano je w dwóch wariantach: na powierzchnię stali (po uprzednim jej przygotowaniu wg standardowej procedury obejmującej czyszczenie elektrolityczne, aktywowanie i nałożenie warstwy podkładowej $\mathrm{Ni}$ - wariant I) oraz powierzchnię ceramiki (po uprzednim osadzeniu chemicznym $\mathrm{Cu}$ lub $\mathrm{Ni}$ - wariant II). Warstwę $\mathrm{Cu}+\mathrm{Al}_{2} \mathrm{O}_{3}$ nakładano $\mathrm{z}$ elektrolitu Copper Alkaline-1, natomiast warstwę $\mathrm{Ni}+\mathrm{Al}_{2} \mathrm{O}_{3}$ z elektrolitu Nickel Extreme High Speed, domieszkowanych nanoproszkiem $\mathrm{Al}_{2} \mathrm{O}_{3}$ o wielkości ziarna $80 \mathrm{~nm}$ w ilości $30 \mathrm{~g} / \mathrm{l}$. Zawartości proszku dobrano na podstawie wcześniejszych prób własnych, mających na celu m.in. dobór parametrów nakładania oraz dobór oprzyrządowania (uchwytów i elektrod). W celu otrzymania pośredniej warstwy gradientowej nakładano kolejno trzy podwarstwy, każdą przy innym napięciu nakładania. Podstawowe parametry nakładania podano $w$ tablicy IV.

Warstwy pośrednie nakładano za pomocą urządzenia DSQ-15, stosując uchwyty elektrodowe ZDB-1(II). Elektrolit podczas nakładania był mieszany $w$ celu utrzymania zawiesiny nanoproszku w elektrolicie.

Otrzymane warstwy pośrednie poddano podstawowym badaniom metalograficznym, wykonano pomiary mikrotwardości oraz określono wielkość krystalitów, wykorzystując wyniki rentgenowskiej analizy fazowej.

Tablica IV. Parametry nakładania pośrednich warstw gradientowych Table IV. The deposition parameters for intermediate FGM layers

\begin{tabular}{|c|c|c|c|c|}
\hline Warstwa pośrednia & Elektrolit & Napięcie nakłac & $\mathrm{a}, \mathrm{V}$ & Czas nakładania (wariant $A$ /wariant $B$ ) s \\
\hline $\mathrm{Cu}+\mathrm{Al}_{2} \mathrm{O}_{3}$ & Copper Alkaline-1 & $\begin{array}{l}\text { podwarstwa } 1 \\
\text { podwarstwa } 2 \\
\text { podwarstwa } 3\end{array}$ & $\begin{array}{c}8 \\
11 \\
14\end{array}$ & $\begin{array}{l}1200 \text { / } 900 \\
900 / 600 \\
600 / 300\end{array}$ \\
\hline $\mathrm{Ni}+\mathrm{Al}_{2} \mathrm{O}_{3}$ & Nickel Extreme High Speed & $\begin{array}{l}\text { podwarstwa } 1 \\
\text { podwarstwa } 2 \\
\text { podwarstwa } 3\end{array}$ & $\begin{array}{c}6 \\
10 \\
14\end{array}$ & $\begin{array}{l}1800 / 900 \\
1800 / 900 \\
1800 / 900\end{array}$ \\
\hline
\end{tabular}


Tablica V. Parametry zgrzewania dyfuzyjnego

Table V. The parameters of diffusion bonding

\begin{tabular}{|c|c|c|c|c|}
\hline Złącza & Temperatura zgrzewania, ${ }^{\circ} \mathrm{C}$ & Czas zgrzewania, s & Docisk, MPa & Próżnia, $\operatorname{Tr}$ \\
\hline Złącza bezpośrednie St3S $-\mathrm{Al}_{2} \mathrm{O}_{3}$ & $\begin{array}{c}800 \\
900 \\
1000 \\
1100\end{array}$ & 1800 & 5 & $10^{-5}$ \\
\hline $\mathrm{St} 3 \mathrm{~S}-\mathrm{Cu}+\mathrm{Al}_{2} \mathrm{O}_{3}-\mathrm{Al}_{2} \mathrm{O}_{3}$ & $\begin{array}{c}800 \\
900 \\
1000\end{array}$ & 1800 & 5 & $10^{-5}$ \\
\hline $\mathrm{St} 3 \mathrm{~S}-\mathrm{Ni}+\mathrm{Al}_{2} \mathrm{O}_{3}-\mathrm{Al}_{2} \mathrm{O}_{3}$ & $\begin{array}{c}800 \\
900 \\
1000 \\
1100\end{array}$ & 1800 & 5 & $10^{-5}$ \\
\hline
\end{tabular}

Badania metalograficzne wykazały prawidłową budowę warstw, z tym, że w przypadku warstwy $\mathrm{Ni}+\mathrm{Al}_{2} \mathrm{O}_{3}$ stwierdzono występowanie niewielkich pęknięć na jej przekroju. Pomiary mikrotwardości wykonano na zgładach przekrojów poprzecznych badanych warstw. Mikrotwardość $(\mathrm{HV} 0,02)$ warstw $\mathrm{Cu}+\mathrm{Al}_{2} \mathrm{O}_{3}$ wynosiła:

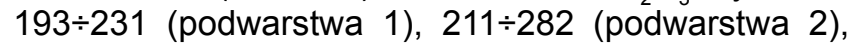
$255 \div 298$ (podwarstwa 3). Dla warstw $\mathrm{Ni}+\mathrm{Al}_{2} \mathrm{O}_{3}$ mikrotwardość zmieniała się od 485 (przy podłożu) do 842 (przy powierzchni warstwy). Wielkość krystalitów $\mathrm{Cu}$ i Ni określono metodą Halla. Dla miedzi wynosiły $15,65 \div 19,41 \mathrm{~nm}$, natomiast dla niklu w granicach $11,08 \div 12,95 \mathrm{~nm}$. Podczas badań zaobserwowano złuszczanie się warstw pośrednich, zarówno $\mathrm{Cu}+\mathrm{Al}_{2} \mathrm{O}_{3}$, jak i Ni $+\mathrm{Al}_{2} \mathrm{O}_{3}$, nakładanych na podłożu ceramicznym (wariant II), świadczące o ich niskiej przyczepności do podłoża.

Zgrzewaniu dyfuzyjnemu poddano walcowe próbki St3S i $\mathrm{Al}_{2} \mathrm{O}_{3}$, o średnicy $10 \mathrm{~mm}$ i wysokości $5 \mathrm{~mm}$. Złącza bezpośrednie $\mathrm{St} 3 \mathrm{~S}_{-}-\mathrm{Al}_{2} \mathrm{O}_{3}$ wykonano w celach porównawczych. Po wstępnych próbach zgrzewania dyfuzyjnego (parametry podano $\mathrm{w}$ tablicy $\mathrm{V}$ ) okazało się, że nie uzyskano poprawnych złączy dla wariantu II. Badania kontynuowano dla wariantu I i temperatur wyróżnionych w tablicy V.
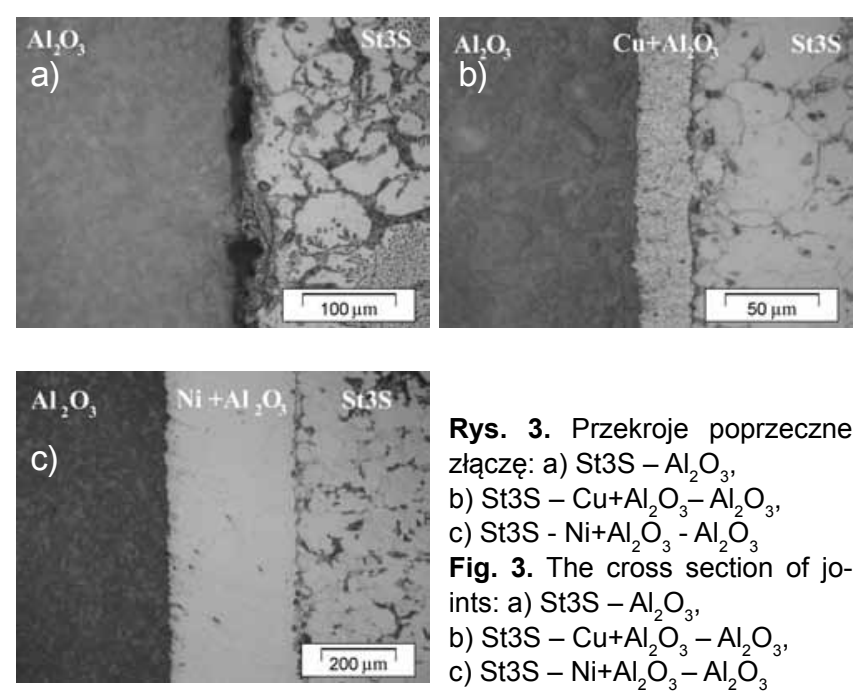

Rys. 3. Przekroje poprzeczne złączę: a) St3S $-\mathrm{Al}_{2} \mathrm{O}_{3}$, b) $\mathrm{St} 3 \mathrm{~S}-\mathrm{Cu}+\mathrm{Al}_{2} \mathrm{O}_{3}-\mathrm{Al}_{2} \mathrm{O}_{3}$, c) $\mathrm{St} 3 \mathrm{~S}-\mathrm{Ni}+\mathrm{Al}_{2} \mathrm{O}_{3}-\mathrm{Al}_{2} \mathrm{O}_{3}$ Fig. 3. The cross section of joints: a) $\mathrm{St} 3 \mathrm{~S}-\mathrm{Al}_{2} \mathrm{O}_{3}$, b) $\mathrm{St} 3 \mathrm{~S}-\mathrm{Cu}+\mathrm{Al}_{2} \mathrm{O}_{3}-\mathrm{Al}_{2} \mathrm{O}_{3}$, c) $\mathrm{St} 3 \mathrm{~S}-\mathrm{Ni}+\mathrm{Al}_{2} \mathrm{O}_{3}-\mathrm{Al}_{2} \mathrm{O}_{3}$
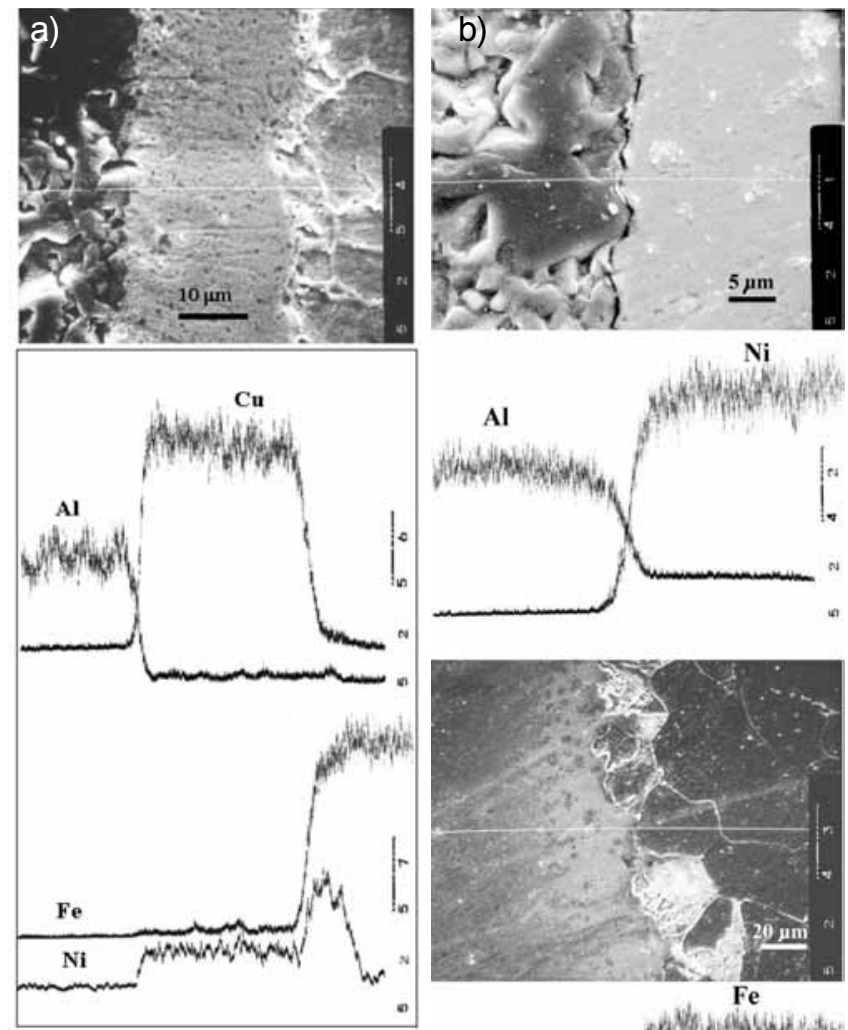

Rys. 4. Rozkłady liniowe pierwiastków złączy:

a) $\mathrm{St} 3 \mathrm{~S}-\mathrm{Cu}+\mathrm{Al}_{2} \mathrm{O}_{3}-\mathrm{Al}_{2} \mathrm{O}_{3}$,

b) $\mathrm{St} 3 \mathrm{~S}-\mathrm{Ni}+\mathrm{Al}_{2} \mathrm{O}_{3}-\mathrm{Al}_{2} \mathrm{O}_{3}$

Fig. 4. Linear elements distribution in joints:

a) $\mathrm{St} 3 \mathrm{~S}-\mathrm{Cu}+\mathrm{Al}_{2} \mathrm{O}_{3}-\mathrm{Al}_{2} \mathrm{O}_{3}$,

b) $\mathrm{St} 3 \mathrm{~S}-\mathrm{Ni}+\mathrm{Al}_{2} \mathrm{O}_{3}-\mathrm{Al}_{2} \mathrm{O}_{3}$

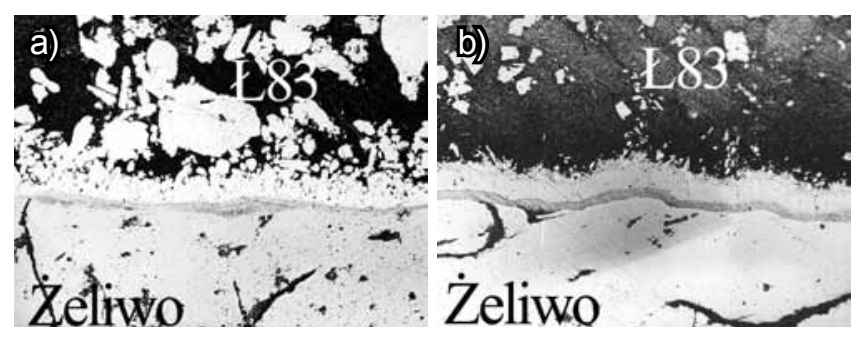

Rys. 5. Warstwa pośrednia w połączeniu żeliwo 250 - stop łożyskowy Ł83 (250x): a) Ni-Cu, b) Ni-Cu-Ni

Fig. 5. Intermediate layer in cast iron - bearing alloy joint (250x): a) $\mathrm{Ni}-\mathrm{Cu}, \mathrm{b}) \mathrm{Ni}-\mathrm{Cu}-\mathrm{Ni}$ 
W ramach badań otrzymanych złączy wykonano podstawowe badania mikroskopowe, badania rozkładów liniowych pierwiastków oraz próby ścinania złącza. Na rysunku 3 przedstawiono przekroje poprzeczne złączy. Zgłady metalograficzne zostały wykonane pod kątem $45^{\circ}$ do płaszczyzny przekroju poprzecznego, a ich powierzchnia poddana została trawieniu. Widoczne są nieciągłości na granicy połączenia St3S $-\mathrm{Al}_{2} \mathrm{O}_{3}$.
Na rysunku 4 przedstawiono rozkłady liniowe wybranych pierwiastków. Widoczna jest dyfuzja niklu i żelaza. Próby ścinania wykonano dla 10 złączy każdego rodzaju. Najwyższą wytrzymałość na ścinanie miały złącza $z$ warstwą pośrednią $\mathrm{Ni}+\mathrm{Al}_{2} \mathrm{O}_{3}(56 \div 70 \mathrm{MPa})$, najniższą złącza bezpośrednie St3S $-\mathrm{Al}_{2} \mathrm{O}_{3}(12 \div 26 \mathrm{MPa})$. Wytrzymałość złączy z warstwą pośrednią $\mathrm{Cu}+\mathrm{Al}_{2} \mathrm{O}_{3}$ mie-

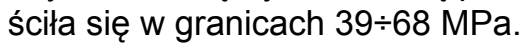

\section{Podsumowanie}

Przedstawione $w$ artykule wyniki prób łączenia metodą zgrzewania dyfuzyjnego wybranych materiałów ceramicznych (ceramika tlenkowa $\mathrm{Al}_{2} \mathrm{O}_{3}$, ceramika azotkowa $\left.\mathrm{Si}_{3} \mathrm{~N}_{4}\right)$ z metalami (Cu(MOOB) i stal St3S) wykazały przydatność stosowania metody tamponowej do wytwarzania warstw pośrednich. Warstwy pośrednie mogą być nakładane jako warstwy metalowe oraz jako warstwy kompozytowe (w tym z gradientem właściwości). Ze względu na znacznie lepszą przyczepność badanych warstw do podłoża metalicznego nie zaleca się ich nakładania na podłoża ceramiczne. $Z$ badanych warstw pośrednich najwyższą wartością wytrzymałości na ścinanie charakteryzowały się warstwy $\mathrm{Ni}+\mathrm{Al}_{2} \mathrm{O}_{3}$.
Warstwy pośrednie nakładane metoda tamponową mogą być stosowane nie tylko przy łączeniu ceramiki z metalami. Jednym z przykładów jest zastosowanie warstw pośrednich $\mathrm{Ni}-\mathrm{Cu}$ i $\mathrm{Ni}-\mathrm{Cu}-\mathrm{Ni}$ w regeneracji panewek żeliwnych (rys. 5).

Stopy łożyskowe o wiele lepiej łączą się z podłożem np. stalowym, niż z podłożem żeliwnym. Stąd głównym celem zastosowania warstwy pośredniej było zwiększenie przyczepności stopu łożyskowego Ł83 (wylewanego metodą odśrodkową) do powierzchni żeliwa szarego ŻL250.

Badania wykazały dobre przyleganie nałożonych warstw i stopu do podłoża.

\section{Literatura}

[1] Włosiński W.: The joining of advanced materials, Oficyna Wydawnicza Politechniki Warszawskiej, Warszawa 1999.

[2] Brush plating solutions instruction manual, China National Machinery Import \& Export Corporation, Beijing Branch.

[3] Grześ J.: Powłoki kompozytowe $\mathrm{Cu}+\mathrm{Si}_{3} \mathrm{~N}_{4}$ i Ni+ $\mathrm{Si}_{3} \mathrm{~N}_{4}$ nakładane metodą tamponową, Kompozyty nr 6/2003, Wydawnictwo Politechniki Częstochowskiej.
[4] Grześ J.: Możliwości metody tamponowej w zakresie nakładania powłok metalowych z gradientem właściwości, Prace Naukowe - Mechanika, z. 215, WPW, Warszawa 2006.

[5] Barlak M., Grześ J.: The functionally gradient materials in the cooper-nickel joints, Proceedings of 6th International Scientific Conference CO-MAT-TECH'98, Trnava 1998.

[6] Grześ J., Pietrzak K.: Spajanie materiałów z wykorzystaniem nanokompozytowych warstw $z$ gradientem składu, Archiwum Nauki o Materiałach, t. 25, nr 4/2003.

\section{Zakład Elementów Sprężystych i Lotniczych Sp z o.o. \\ ul. Podskarbińska 32/34 lok. 44, 03-829 Warszawa \\ tel.: 2281056 49, fax.22 81080 14, \\ www.kompensatory-mieszkowe.pl, info@kompensatory-mieszkowe.pl}

\section{ZESiL Sp. z 0.0. oferuje usługi:}

- lutowania twardego przy użyciu lutów srebrnych, mosiężnych i miedziano-fosforowych,

- lutowania miękkiego lutami cynowymi,

- montażu elementów z wykorzystaniem technik lutowania (w tym elementy ciśnieniowe i próżniowe). 